\title{
Pós-Modernidade, Secularização e o Pentecostalismo Assembleiano no Brasil
}

\author{
Post-Modernity, Secularization and Assembly \\ Pentecostalism in Brazil
}

James Washington Alves dos Santos ${ }^{1}$

\begin{abstract}
Resumo
Este artigo aborda os conceitos de pós-modernidade e secularização em sua relação com o modelo pentecostal das Assembleias de Deus no Brasil. Salvo a polissemia institucional ligada a esta denominação, em terras brasileiras, o que buscamos é mostrar como estes dois conceitos são usados de maneira geral para evidenciar uma crise nos valores morais e criar um ambiente social onde a tônica é a decadência da prática religiosa. Neste sentido propomos a problematização do uso destes conceitos no campo religioso brasileiro, explicando as confusões que estão envolvidas no uso indiscriminado destas proposições, além de mostrar que as práticas religiosas trazidas pelo pentecostalismo assembleiano acabaram por desenvolver o campo e o mercado religioso no Brasil e na América Latina.
\end{abstract}

Palavras-Chave: Pós-modernidade. Secularização. Pentecostalismo. Cristianismo.

\section{Abstract}

This article addresses the concepts of postmodernity and secularization in its relation to the Pentecostal model of the Assemblies of God in Brazil. Except for the institutional polysemy linked to this denomination, in Brazilian lands, what we seek is to show how these two concepts are used in a general way to highlight a crisis in moral values and to create a social environment where the tonic is the decadence of religious practice. In this sense, we propose the problematization of the use of these concepts in the Brazilian religious field, explaining the confusions that are involved in the indiscriminate use of these propositions, besides showing that the religious practices brought about by Pentecostalism assembled the field and the religious market in Brazil and in the Latin America.

\footnotetext{
${ }^{1}$ Doutorando em Ciências Sociais. Universidade Estadual Paulista Júlio de Mesquita Filho, UNESP, Brasil.
} 
Keywords: Postmodernity. Secularization. Pentecostalism. Christianity.

\section{Introdução}

Este artigo aborda os conceitos de pós-modernidade e secularização em sua relação com o modelo pentecostal das Assembleias de Deus no Brasil. Isso nos coloca diante do fato de que a pós-modernidade para os assembleianos é invocada como período histórico atual, permeado por dois fenômenos que são vistos como nocivos, a saber: o sincretismo e o relativismo. Salvo a polissemia institucional ligada a esta denominação, em terras brasileiras, sua forma de ver a pós-modernidade parece diacrônica em relação a sua própria realidade e seu projeto de expansão territorial e eclesial. Por um lado as AD's invocam a ideia de geral de crise dos valores morais, portando, invocam um cenário propício para a decadência da prática religiosa. Em complemento, se colocam como promotoras de um proselitismo salvador, como antidoto direto ás mazelas que o mundo pós-moderno traria, sem assumir de fato, que as formas de se viver a religião institucionalizada estão imersas nesse mundo pós-moderno, ou seja, já sofrem o processo de secularização.

Neste sentido, primeiro problematizamos o uso do conceito de pósmodernidade comparando com o chamado período histórico moderno. O intuito é de mostrar as diferenças entre os dois conceitos para dirimir confusões que estão envolvidas no uso indiscriminado do primeiro. Numa segunda parte, mostraremos que as mudanças nas formas de vivência do sagrado estariam mais relacionadas aos efeitos da secularização do que da pós-modernidade. Por último, separamos uma terceira parte para abordar algumas evidências da força das práticas religiosas no Brasil e na América Latina, propondo um questionamento a ideia de decadência das práticas religiosas. Pelo contrário, acreditamos em seu fortalecimento que se alicerça através de uma tentativa corrente de afirmação de uma fonte simbólica de 
poder, que combina aspectos teológicos e práticos, seguindo a linha do crescimento em meio à diversidade de segmentos pentecostais.

\section{Idade Moderna e Modernidade}

Por Idade Moderna entende-se o período histórico que teve início com a queda do regime feudal (por meio da crise na produção agrícola, surto de peste bubônica e conflitos entre senhores feudais pela busca de poder e ampliação de território). Estes fatores fizeram com que no final do séc. XIV a configuração geopolítica da Europa não só criasse as condições para o advento dos Estados Nacionais (Portugal, Espanha, Inglaterra, França, Holanda e outros), que foram à síntese de territórios feudais unificados, como também as grandes navegações, o capitalismo comercial e as mudanças nas relações de trabalho (de servil para livre concorrencial).

Assim, a Idade Moderna enquanto período histórico rompe com a fisiocracia (o poder é consolidado pela posse da terra) e define o surgimento de territórios políticos comandados por reis, bem como o advento das cidades comerciais racionalizadas (ou seja, que buscam o lucro e um desenvolvimento constante e calculado). Além disso, os nobres e os mestres de ofício da época contavam com a obediência e o trabalho dos súditos e dos oficineiros, que com o passar do tempo passou a ser cada vez mais segmentado (o advento gradativo da divisão do trabalho social).

Apresentado o período moderno, cabe definir que ele tem o seu fim com a Revolução Francesa de 1789, o que demonstra a crise do Estado monárquico e a gênese de novas formas de organização política (Czarismo, Repúblicas e Governos revolucionários provisórios). No entanto o legado deste momento é justamente um processo de desenvolvimento econômico, político e social, que ultrapassa o limite de 1789 e ainda hoje se faz presente, é justamente aquilo que chamamos de modernidade. 
A modernidade é um processo de formação de novos modelos políticos que ultrapassaram a liderança feudal, os reinados inspirados em situações metafísicas e religiosas e acima de tudo uma busca pelo desenvolvimento científico e a especialização das atividades laborais. Isso começou no fim da Idade Média e até hoje vemos o desenvolvimento cientifico corrente, uma forte divisão do trabalho, com especialistas das mais diversas áreas do conhecimento, além da tentativa corrente de firmar a laicidade do Estado. Afinal de contas o que existe não seria uma confusão em entender a definição e o alcance dos conceitos de Idade Moderna (enquanto período histórico) e modernidade (enquanto processo não acabado)?

Aqui faço menção a Anthony Giddens e Manuel Cardoso de Oliveira. O primeiro é britânico, membro da Universidade de Economia de Londres e defende que o que vivemos no meio social pode ser chamado de modernidade tardia, ou seja, o que foi começado no séc. XIV está sendo posto em desenvolvimento, debate, questionamento (o trabalho, o Estado laico, a Ciência), contudo, estes assuntos não foram superados. Então fica a pergunta, onde está a pós-modernidade?

Outra questão é o deslocamento rápido. Para termos uma ideia, Anthony Giddens (1991) trata justamente da constatação de que a modernidade tardia é um momento de ápice de questões como o tratamento ao tempo e do espaço. Se no séc. XIV as grandes navegações criaram a possibilidade de deslocamento, hoje estas possibilidades são instantâneas por meio das Tecnologias da Informação e Comunicação (TIC), e bem mais eficazes nos avanços ligados a área dos transportes.

Por sua vez, Manuel Cardoso de Oliveira (1990) é enfático ao afirmar que mesmo diante destas mudanças e avanços, a America Latina ainda é periférica em relação ao desenvolvimento do capitalismo. Isso nos é revelador, pois temos como consequência direta o atraso em relação à produção de tecnologia e diversidade de vias para transporte de cargas e 
passageiros e no lado comportamental, possibilidades de manutenção de determinadas tradições (inclusive as religiosas). Em outras palavras, o comportamento latino e por consequência brasileiro, não é a priori um dos mais liberais considerando a maioria absoluta da população mundial em seus contextos próprios.

Nisto mora o perigo de se usar as formulações teóricas baseadas na ideia de pós-modernidade. As mais perigosas são: o tratamento do ser humano como um sistema, a questão do fim das meta narrativas e a consolidação do individualismo pleno. No primeiro ponto, temos como defensor direto, Niklas Luhmamm (2011). Para ele os indivíduos seriam sistemas auto-reguláveis que se adaptam as situações naturais e sociais como sujeitos sempre voltados para escolhas racionais. Contudo, cabe lembrarmos que a religião (e nos referimos à cristã), tem um potencial de formar um consciente coletivo que emana força e pode criar uma corrente social em resistência aos comportamentos mais liberais, trazendo aos poucos alguns que se diziam resistentes a mensagem. Além disso, o código de regras e conduta cristã (a Bíblia) é visto como definidor de um padrão a ser seguido mesmo que alguns apelem para as manobras radicais da hermenêutica. Com isso já podemos afirmar que a grande narrativa bíblica não está superada. Se estivesse, a pregação, defendida como inspirada pelo Espírito Santo não surtiria efeito e muitos não a tratariam como "lei dos crentes".

\section{O fator de corrosão da fé na modernidade tardia: a Secularização}

Um dado que não pode ser esquecido é a forte presença de um resgate das tradições dentro do pentecostalismo brasileiro por meio das Assembleias de Deus. Vários líderes assembleianos são originários de ambientes rurais onde a tradição que rege as formas de comportamento parece ainda resistir 
ao ideal da liberdade religiosa e comportamental. Por esse motivo, o "Eclipse do sagrado" ou "Secularização", previsto por Sabino Samele Aquaviva parece não se cumprir plenamente diante de um Brasil que mescla a modernização lenta do setor industrial ao modo arcaico de suas relações societais. Neste sentido, o referido "eclipse" não teria aqui uma função destruidora, mas, tentaria de todas as formas transformar o "universo religioso", não anulandoo mas provocando em seu meio um novo modo de ser cristão.

A secularização, como processo, pode, por si, dar vida a novos modos de ser religioso. É claro que, se a religião for despojada de suas formas exteriores, ela termina por permitir, exatamente por que mudam as 'regras do jogo', novos modos de viver a experiência do sagrado [...]. Com a secularização, a religiosidade (assim como a religião) muda de qualidade e diminui em intensidade (AQUAVIVA, 1992, p. 7-9).

O desafio para as Assembleias de Deus enquanto segmento pentecostal e sectário é manter-se durante sua história (e não apenas em seus primórdios) resistente ao processo de secularização. Neste sentido, o impacto da secularização está como afirma David Martin (1969, p. 9), no fato desta ser um processo unilinear e irreversível, "ele está ligado aos contextos particulares, sendo complexo e ambíguo em seu movimento". Ele também considera que este processo de secularização deve ser estudado com base no próprio comportamento dos indivíduos, nas suas relações com o sagrado.

Diante desta questão, faz-se necessária a compreensão de que o movimento de secularização não deve ser entendido, como já dissemos como movimento de destruição e sim uma tentativa de transformação da esfera religiosa. Seguindo esta mesma linha, Karel Dobbelaere (1981) enfatizará o caráter multidimensional da secularização, decompondo-a em três níveis, a saber:

a) o societal: descritível como laicização (expressa pela diferenciação das instituições, motivo pelo qual a instituição religiosa perde seu caráter universal e se torna uma instituição como as outras); 
b) o institucional: representado pela mudança religiosa interna (com a modernização e a mundanização da religião);

c) e o individual: constituído pelo envolvimento religioso (tem estreita ligação com a decadência da prática religiosa).

Assim o conjunto de regras impostas pela tradição das Assembleias de Deus encontraria segundo Karel Dobbelaere uma "tripla resistência", o que não elimina o fato das regras ainda terem uma força consistente. Esta força, por sua vez, é derivada de toda uma série de orientações contidas nas tradições e na Bíblia. As orientações contidas neste conjunto de livros visam estabelecer um padrão das práticas religiosas, onde a fidelidade aos preceitos dados se coloca como o meio eficaz para guiar a conduta humana, tanto em relação às interações sociais quanto ao alcance do prêmio que é oferecido: a própria salvação (ou o chamado bem de salvação, para usar uma expressão weberiana). Para exemplificar esta afirmação, vejamos o que a própria denominação comenta a respeito do potencial da chamada "palavra da

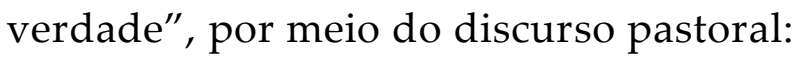

A igreja deve manifestar toda a verdade da palavra de Deus: 'Pelo que, tendo este ministério, segundo a misericórdia que nos foi feita, não desfalecemos; antes, rejeitamos as coisas que, por vergonha se ocultam, não andando com astúcia nem falsificando a palavra de Deus; e assim nos recomendamos à consciência de todo homem, na presença de Deus, pela manifestação da verdade' (2 Co 4. 1,2). Os obreiros, principalmente os pastores, tem grande responsabilidade diante de Deus e de sua amada igreja. O púlpito jamais deve ser utilizado como palanque político, mas, sim, como tribuna da verdade do evangelho. Todo líder deve conduzir seu rebanho com completa obediência a palavra da verdade (LIMA, 2008, p. 59).

Desta forma é possível vislumbrar a fonte material e ao mesmo tempo simbólica e espiritual (a Bíblia) de onde emana na forma escrita as regras de conduta que visam orientar a vida dos fiéis assembleianos. Analisando esta questão, Henri Bergson (1978, p. 72) vai mostrar que no ambiente religioso, teríamos a existência de duas fontes de moral religiosa, a saber: a fechada 
(possibilitando uma religião estática) e a aberta (possibilitando uma religião dinâmica). "Na moral fechada e na religião estática, entre proibições, hábitos e routine, domina o cálculo conservador do grupo que talvez produza coerção mecânica, e que, ao mesmo tempo, impede a liberdade plena dentro da religião". Por outro lado, "na moral aberta e na religião dinâmica, a negação da ordem e a ruptura da passividade do hábito nascem do impulso que apenas sabe testemunhar e promover a criação contínua de novas formas de vida e de ser". Enquanto crítico ferrenho da imposição doutrinária, Henri Bergson defende a ideia de uma religião aberta, onde a coerção daria lugar a criatividade e liberdade das pessoas. Assim ele se posiciona e ao mesmo tempo afirma a existência destas duas fontes da moral e da religião presentes nos contextos sociais, e que no caso assembleiano sabemos que a primazia está na forma religiosa entendida por Bergson como estática (isso dentro da maioria das $\left.\mathrm{AD}^{\prime} \mathrm{s}\right)$, perseverando com ela a moral em sua forma fechada.

Reconhecemos a importância de Henri Bergson, mas, avançando um pouco em direção as propostas teóricas que ressoam como alternativas a doutrinação religiosa, temos a proposta de Thomas Luckmann com o seu conceito de religião invisível. Luckmann é um teórico filiado às correntes de pensamento fenomenológica e pragmática, representadas respectivamente pelas figuras de Alfred Schutz e Georg Herbert Mead. Neste sentido sua preocupação é com a Sociologia do Conhecimento e mais propriamente com as "concepções de mundo, enquanto realidade social 'objetiva' e histórica" (LUCKMANN, 1969, p. 69). Por isso ele argumenta sobre a existência de uma "divergência potencial" entre o modelo oficial de religião e o comportamento subjetivo, que dá significação a realidade social. Ele opta claramente pela defesa da auto-expressão e auto-realização dos sujeitos, elementos que juntos, formam um conjunto que engloba também a independência individual e a mobilidade, fechando assim, o conjunto dos pressupostos basilares de sua religião invisível, contraposta à religião visível, que segundo ele, constituiu-se 
como objeto tradicional de uma Sociologia da Religião atenta apenas a medir o nível de prática festiva e sacramental.

Este caminho traçado por Thomas Luckmann foi identificado por Peter Berger como tendo dois processos: o primeiro de secularização e o segundo de plurarismo. No primeiro processo, temos o declínio da credibilidade das instituições religiosas, e no segundo, temos a existência de uma pluralidade de crenças, que podem advir de concepções políticas ou nacionalistas, servindo estas de concorrência aos grupos religiosos existentes. Formando a princípio um dueto com Luckmann, Peter Berger (1984, p. 72) dirá que a secularização age em prol da remoção da dominância religiosa de diversos setores da sociedade e da cultura, acrescentando ainda que:

Está comprovado que hoje, o sobrenatural como realidade significativa está ausente ou remoto do horizonte da vida cotidiana de muitíssimos homens, para não dizer talvez da maioria deles que vivem na sociedade moderna. Eles parecem, com efeito, poder facilmente descartar-se dele. Isso significa que aqueles para os quais o sobrenatural é ainda, ou novamente, uma realidade significativa, acabam se encontrando em uma situação de minoria.

Neste momento Berger mantém-se fiel aos pressupostos da Sociologia do Conhecimento, concebendo a ideia de liberdade do sujeito frente às crenças no sobrenatural, e com isso, crê na sua emancipação. Contudo, anos mais tarde (mais propriamente na década de 1990), ele mudará de opinião com relação à ideia de secularização enquanto movimento amplo e consistente, afirmando que:

Argumento ser falsa a suposição de que vivemos em um mundo secularizado. $\mathrm{O}$ mundo de hoje, com algumas exceções [...], é tão ferozmente religioso quanto antes, e até mais em certos lugares. Isso quer dizer que toda uma literatura escrita por historiadores e cientistas sociais vagamente chamada de 'teoria da secularização' está essencialmente equivocada. Em trabalhos anteriores, contribuí para essa literatura. Eu estava em boa companhia a maioria dos sociólogos da religião tinha opiniões semelhantes, e nós tínhamos boas razões para afirmá-las. 
Algumas das obras produzidas ainda se sustentam. Como gosto de dizer a meus alunos, a vantagem em ser cientista social em vez de filósofo ou teólogo é que podemos nos divertir tanto quando nossas teses são refutadas quanto quando são confirmadas! (Id. 2000, p. 10).

Isso mostra que a análise sociológica deve estar atenta as nuances que o processo de secularização pode ter. Chamamos de processo justamente pelo fato deste fenômeno ter se colocado de maneira peculiar dependendo da figuração social a qual se aproxima. Neste caso, concordamos com a existência da secularização, mas a realidade de uma maioria avessa às regras religiosas ainda não é o nosso modelo de sociedade, principalmente diante de uma igreja como as Assembleias de Deus, que empreendem sem cessar uma corrida visando converter pessoas para a doutrina cristã levando-as a buscar uma vida um modus operandi próprio nos aspectos da vida material, profissional e espiritual.

\section{O sentido do pentecostalismo assembleiano: nem tudo está perdido!}

É fato que estarmos numa América Latina resistente ao processo de secularização (apesar de Habermas radicalizar afirmando que o contexto europeu já vive em uma sociedade pós-secular), o fato é que como argumentara Durkheim (1989), as religiões formam (como no caso do contexto latino) através do pentecostalismo, um espectro social que criou um verdadeiro sistema de classificação do mundo, formando cosmologias em torno dos dons espirituais que operam numa dualidade conceitual básica: estar envolvido pelo sagrado ou "perdido" em torno do profano. Constatarmos com isso a presença das religiões como explicação do mundo gerando por isso mesmo três questões:

a) os consensos lógicos; 
b) os consensos morais;

c) um sistema cosmológico próprio.

Num exemplo prático poderíamos citar o pentecostalismo de cunho pré-milenial. Aquele em que estão inseridas as Assembleias de Deus. Nesta concepção escatológica (que é uma verdadeira mecânica da salvação de cunho arminiano, ou seja, que privilegia o livre arbítrio) haverá separação dos escolhidos e não escolhidos por Jesus havendo por isso um fenômeno chamado arrebatamento (que consiste no sumiço destes escolhidos da terra e a garantia de sua salvação). Não me alongarei explicando os acontecimentos que serão consequência deste primeiro, a saber: a Grande Tribulação, a Guerra do Armagedon, o Reino Milenial de Cristo na terra e o grande Juízo Final. Não é nossa intenção detalhar estes eventos, mais apenas citá-los como fizemos, no intuito de mostrar os efeitos desta narrativa. São aproximadamente hoje, 18 milhões de assembleianos no Brasil, para citar a corrente majoritária dos pentecostais, que acredita, salvo uma boa parte que ainda titubeia neste quesito, nos eventos que acabamos de citar. Estatisticamente segundo dados da pesquisa Datafolha (2017), as AD's equacionam $22 \%$ dos evangélicos no Brasil, de um total de $32 \%$. Dentro ainda deste universo vemos aos poucos a evidência dos afeitos da Teologia da Prosperidade dentro de seu arcabouço teológico, formando mesmo que num cenário interno, divergências constantes e cada vez mais um clima acirrado e competitivo.

Em uma de minhas visitas ao templo da Assembleia de Deus em Araraquara no dia 17/06/2018, pude ouvir a pregação do pastor G. S. que tocava na seguinte questão, quanto o papel e a postura dos crentes (evangélicos) nas igrejas:

Estamos diante de um tempo em que não podemos mais brincar. Aquelas dez virgens que pela cultura judaica eram amigas da noiva. Estavam junto a ela esperando o noivo para que fossem junto com ele para a festa. Está claro que isto é 
uma alegoria, para dizer que todo crente deve estar preparado, não apenas com sua lâmpada, mais principalmente com o combustível para mantê-la sempre acessa, ou seja, deve ter o seu azeite. Não apenas o necessário, mas principalmente azeite de reserva. Isso não se tem comprando, isso se obtém por meio da oração e da obediência.

O apelo aos dois aspectos centrais do processo de conversão faz sentido (a oração e a obediência) na medida em que fazer parte de uma instituição religiosa seria em primeiro ponto uma forma de submissão ás regras institucionais transvestidas de preceitos divinos. $\mathrm{O}$ detalhe é que mesmo o mais puro culto retirado da consciência individual, para Durkheim (1989) é fruto no fim as contas da construção coletiva que é sua origem. Ou seja, a sociedade cria, cultua e cultiva a existência dos símbolos que forma. Por isso a importância da relação: sacerdote/seguidores/súplicas em detrimento da relação: mago/cliente/comandos.

Mas a negação da magia é algo puramente formal. Por isso ainda é válida a pergunta durkheimiana: existiria religião mágica? Nossa resposta é que sim! Temos religiões mágicas hoje e os exemplos particulares do Brasil não são poucos. Isso criou também como diria Berger (1984), um verdadeiro mercado religioso, com possibilidades que de uso de dons espirituais, operações de milagres, determinação das benções via confissão positiva. Além do próprio leque de possibilidades de filiações ampliado.

Para fecharmos esta questão, Durkheim (1989) se pergunta qual o futuro da religião? Hoje em parte, no que se refere ao Brasil, é possível termos uma descrição e ela nos revela um contexto social majoritariamente cristão.

Quadro 1 - Número de adeptos em cada segmento: censo demográfico de 1940 a 2010 e pesquisa Datafolha 2017.

\begin{tabular}{|l|l|l|l|l|l|l|}
\hline Censos & Católicos & Evangélicos & $\begin{array}{l}\text { Sem } \\
\text { religião }\end{array}$ & Espíritas & $\begin{array}{l}\text { Religiões } \\
\text { Afro }\end{array}$ & Outras \\
\hline $\mathbf{1 9 4 0}$ & 95,2 & 2,6 & 0,2 & - & - & - \\
\hline
\end{tabular}


Religare, ISSN: 19826605, v.15, n.1, agosto de 2018, p.243-259

\begin{tabular}{|l|l|l|l|l|l|l|}
\hline $\mathbf{1 9 8 8}$ & 89,0 & 6,6 & 1,6 & 0,7 & 0,57 & - \\
\hline $\mathbf{1 9 9 1}$ & 83,3 & 9,0 & 4,7 & 1,1 & 0,44 & - \\
\hline $\mathbf{2 0 0 0}$ & 73,9 & 15,6 & 7,4 & 1,3 & 0,34 & - \\
\hline $\mathbf{2 0 1 0}$ & 64,6 & 22,2 & 8,0 & 2,0 & 0,30 & 3,2 \\
\hline $\begin{array}{l}\mathbf{2 0 1 7} \\
\text { *Pesquisa } \\
\text { Datafolha }\end{array}$ & $\underline{\mathbf{5 2 , 2}}$ & $\underline{\mathbf{3 2}, \mathbf{0}}$ & 9,0 & 4,0 & - & 3,0 \\
\hline
\end{tabular}

Fonte: Ricardo, 2013.

Contrariando a ideia de que a religião poderia se fortalecer em torno de seus próprios dogmas, Berger (1984) pensava que com o desenvolvimento da modernidade e de seus setores secularizados perante a realidade histórica e social, cada vez mais a religião iria ao encontro de elementos não religiosos que dessem sentido a vida, inclusive influenciando ela mesma em detrimento as suas teologias. Desta forma acabariam absorvendo elementos da Psicologia e de outras ciências modernas em suas análises. A questão é que estamos em um país composto por $82,2 \%$ de cristãos e se considerar o fluxo de duplas ou triplas filiações com segmentos como a umbanda e o candomblé este percentual possivelmente aumenta. É aquilo que Mariz (2001) chama de um diálogo na base, ou seja, por meio de processos ligados ao ecumenismo, com suas trocas simbólicas, para usar um conceito de Bourdieu (1974), Mariz coloca a questão de um fluxo e uma troca de referências entre membros denominações religiosas, inclusive as pentecostais.

Isso definiria a possibilidade de membros de denominações, em detrimento da cúpula, participar de reuniões e cultos de outras matrizes sem negar e localizar a sua filiação há uma determinada referência. É interessante perceber como isso vai dialogar com a postura dos dirigentes que de antemão, preservando sua instituição diante do mercado religioso se colocam mais resistentes ao diálogo por uma lógica de "competição por fieis". Contudo, 
este quadro muda, quando se fala em uma luta conjunta em torno de questões éticas da religião. Com isso entraríamos no campo da defesa da moralidade religiosa por meio do campo político e união entre igrejas contra os inimigos comuns: "esquerdistas", "laicistas", "profanos" etc. Em termos objetivos, este jogo interno ao pentecostalismo funcionaria da seguinte forma:

Figura 1 - Relações entre lideranças, membresia e diálogo inter religioso brasileiro (perfil pentecostal).

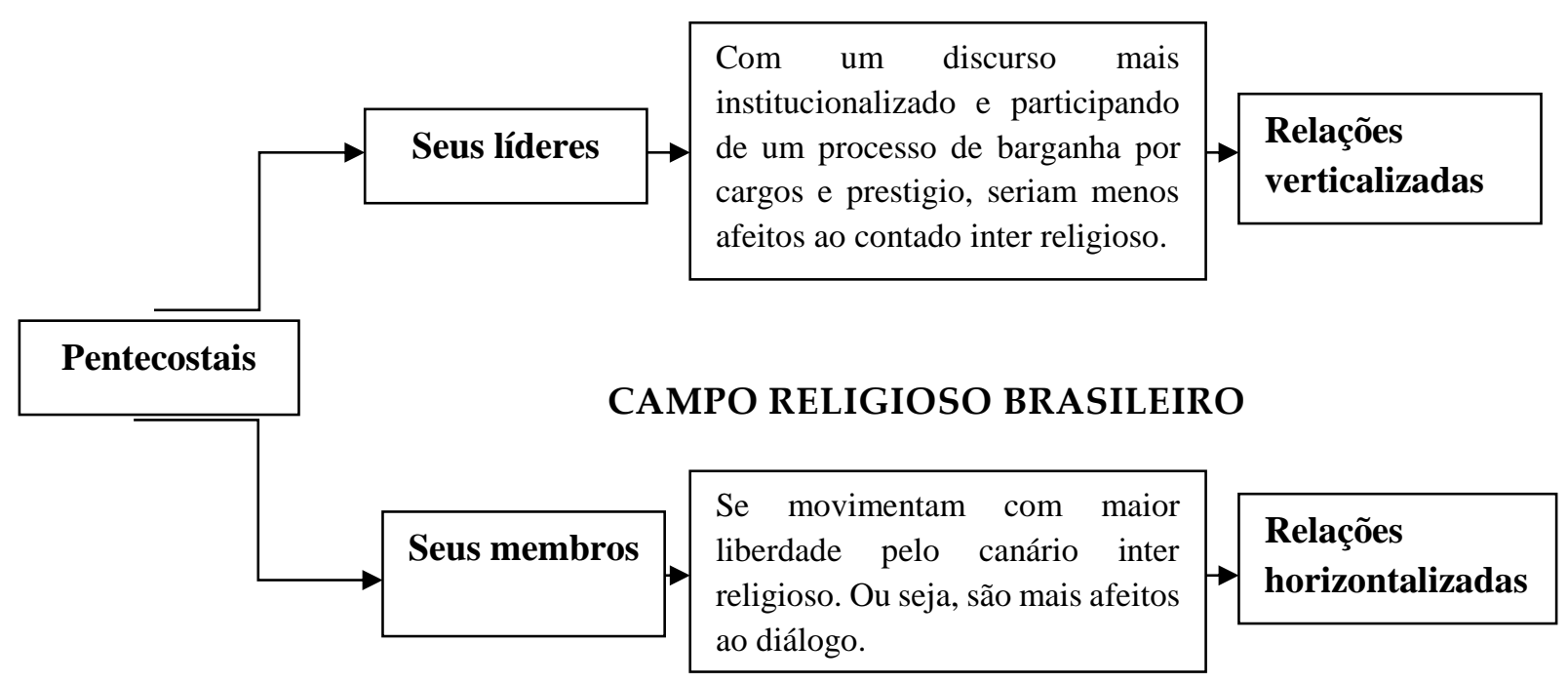

Fonte: o autor.

Esta relação dentro do campo religioso brasileiro revela em larga medida as estratégias que diferem conforme o segmento analisado. A que se dizer, contudo, que a importância da religião acaba por ser diretamente proporcional a forma como as cosmologias estão interagindo dentro das consciências individuais, formando maneiras ora mais compostas, ora mais particulares, ora verdadeiros "mosaicos de crenças" geradores de "cosmologias fragmentadas", ora verdadeiras "teologias autocráticas" geradoras de "cosmologias particularizadas". Esta ideia não corrobora com o cenário descrito por Bourdieu (1974), que mais lembra uma mão unica entre produtores e consumidores de simbologia religiosa, não negando que os consumidores são 
potenciais produtores, porém colocando-os em uma condição de expropriados de seu produto simbólico que é a crença religiosa. Não queremos com isso afirmar que a produção e o consumo de simbologia religiosa deixe de existir, mais sua apropriação será feita pelos membros do próprio grupo, não mais com uma referência única (o líder, que emana legitimidade institucional), mais como uma verdadeira luta de campo, entre a produção individual, coletiva e institucional, montando este verdadeiro mosaico que mencionamos e fragmentando progressivamente o entendimento sobre o mundo.

Neste sentido, há em nossa época histórica e contexto latino americano não só uma circulação maior (ou trânsito religioso), como também uma disposição ao diálogo, para além dos ditames institucionais. Poderíamos seguir mencionando que relação este fenômeno estabelece com as nuances do trabalho religioso, mais isso seria ponto a ser discutido em outro texto.

\section{Conclusão}

Em relação a este artigo, por hora apresentamos já em seu inicio, uma refutação ao conceito de pós modernidade enquanto categoria válida para se pensar o contexto Latino Americano, principalmente no que se refere as suas conotações mais fluidas, com a ideia de uma descontinuidade das meta narrativas, por exemplo.

Num segundo momento procuramos fazer uma exposição do que acreditamos ser a categoria mais mobilizada pelos sociólogos da religião que é justamente o fenômeno da secularização, com suas composições e efeitos. Neste sentido não só Berger, mas como ele mesmo comenta, outros tantos sociólogos da religião na década de 1980, acreditavam na secularização como fenômeno que abarcaria o religioso, mudando o seu sentido e o enfraquecendo. Porém, a tendência que se evidencia principalmente do 
contexto latino foi o de efervescência religiosa por meio do pentecostalismo implicando diretamente em uma postura anti moderna e uma minimização dos "ventos secularizantes" pela dinâmica do usos dos dons, as performances midiáticas e o seu alcança das diversas camadas sociais, o que demonstrou uma forma própria de se desenvolver.

Como consequência disso, teremos aquilo que Berger (1984) colocara em seus estudos relacionados aos EUA como mercado religioso. Em outras palavras, ao invés de termos um refluxo do campo religioso, abafado por uma era dos conhecimentos científicos e os efeitos da modernidade, o que ocorre é uma expansão deste campo, gerando uma gama de opções de crença, revitalizando e dinamizando expressões, provocando concorrência e impactando outros setores da sociedade para além da religião, a saber: a política, a economia, a estética. Neste sentido, finalizamos um breve artigo e não uma discussão bem mais ampla sobre o momento em que vivemos, momento este que nos serve de reflexão quanto aos rumos da religião na América Latina e seu conjunto de expressões.

\section{Referências}

ALMEIDA, João Ferreira de. (Org.). Bíblia de Estudo Pentecostal. 24. ed. rev. e corr. Rio de Janeiro: CPAD, 1995.

AQUAVIVA, Sabino Samele. L'eclissi del sacro nella civita industriale. Milão: Comunitá, 1992.

BERGER, Peter. A dessecularização do mundo: uma visão global. Revista Religião e Sociedade. Rio de Janeiro, p. 9-24, 2000.

. La sacra volta: elementi de uma teoria sociológica della religione. Milão: Sugar, 1984.

. O dossel sagrado: Elementos para uma teoria sociológica da religião.

São Paulo: Paulinas, 1984.

BERGSON, Henri. As duas fontes da moral e da religião. Rio de Janeiro: Zahar, 1978.

BOURDIEU, Pierre. Gênese e estrutura do campo religioso. In.: A economia das trocas simbólicas. São Paulo: Editora Perspectiva, 1974.

DOBBELAERE, Karel. Secularization: a multi-dimensional concept. Nova York: Current Sociology, 1981. 
DUKHEIM, Émile. As formas elementares da vida religiosa. São Paulo: Paulinas, 1989.

GIDDENS, Anthony. Consequências da Modernidade. São Paulo: Editora da UNESP, 1991.

LIMA, Elinaldo Renovato de. A Bíblia: o código de ética divino. Lições Bíblicas. Rio de Janeiro: p. 49-52, 4. Trimestre, 2008.

LUCKMANN, Thomas. La religione invisible: Bolonha: Il Munilo, 1969.

LUHMANN, Niklas. Introdução à teoria dos sistemas. Petrópolis: Vozes, 2011.

MARIZ, Cecilia Loreto. Secularização e dessecularização: comentários a um texto de Peter Berger. Religião e Sociedade. Rio de Janeiro. v. 21, 2001, no 25-40.

MARTIN, David. The Religious and the secular: studies in secularization. Londres: Routledge \& Kegan Paul, 1969.

OLIVEIRA, José Manuel Cardoso de. O Capitalismo Tardio. Brasília: Editora da UNB, 1990.

SOUZA, André Ricardo de. Traços e embaraços do trabalho assistencial cristão. Estudos de Sociologia. V. 18, nº 34, 2013, p. 173-192. 